\title{
Assessing the impact of energy efficiency measures on load diagram shape-a case study in the Portuguese residential sector
}

\author{
José Luís Sousa (D) António Gomes Martins (iD. \\ Rodrigo Luiz da Costa
}

Received: 5 April 2021 / Accepted: 13 September 2021 /Published online: 16 November 2021

(C) The Author(s) 2021

\begin{abstract}
This paper intends to address the effect of energy efficiency and load management measures on load diagrams. In order to assess this specific impact, diagrams of load variations caused by energy efficiency measures are proposed. A case study is used to illustrate the effects of energy efficiency measures implemented under the Portuguese plan for the promotion of efficient electricity use (PPEC). The diagrams of load variations were estimated for measures targeting the residential sector which were approved in the six PPEC editions launched until presently. The measures were grouped according to the targeted energy service. The results of this case study indicate that energy distribution operators can change their load diagram by implementing energy efficiency measures in consumer dwellings, with demand reduction at critical periods. It is shown that energy
\end{abstract}

J. L. Sousa $(\bowtie)$

Polytechnic Institute of Setúbal/Technology School of Setúbal, SustainRD - Research Center for Engineering and Sustainable Development, INESC, Coimbra, Setúbal, Portugal

e-mail: jose.luis.sousa@estsetubal.ips.pt

\section{A. G. Martins}

Energy for Sustainability Initiative, Department of Electrical and Computer Engineering, INESC Coimbra, University of Coimbra, Coimbra, Portugal

e-mail: agmartins@uc.pt

R. L. da Costa

Electronics Department, Federal Institute of Santa

Catarina, Florianópolis, Brazil efficiency in lighting measures can help smoothen the evening demand peak at 10 p.m. On the other hand, the effect of hot water measures, although beneficial in terms of energy saving, may increase the negative power gradient occurring at 9 a.m. due to photovoltaic generation under clear sky conditions. Diagrams of load variations can help to estimate the impact of energy efficiency measures on the network load diagram and can give important information for decision support to the distribution system operator, the utilities, and the energy regulator.

Keywords Diagram of load variation · Energy efficiency measures · Residential sector energy demand · Portuguese energy policy

\section{Introduction}

Distributed energy resources (DER), such as smallscale renewable electricity generation, energy storage, and demand management, are presently the focus of energy policies and regulatory activity throughout the world due to their recognized capability of increasing the flexibility of system management. This circumstance is a strong incentive to technological innovation and development and to the definition of regulatory incentive schemes which aim to foster the use of DER. Due to this trend, distribution utilities may face difficulties regarding revenues, profitability, and cost reduction. In fact, the falling costs of distributed 
generation and storage technologies, the increasing interest in demand-side management options, and the decreasing rate of growth of electricity demand, among others, represent disruptive challenges to distribution utilities (Kind, 2013).

With the deployment of DER, mainly photovoltaic (PV) electricity, the load curve in several geographies (Denholm et al., 2015; Rai et al., 2019), as seen by grid utilities, is changing from "camel" shape to "duck" shape, as seen in Fig. 1, rising new revenue and operational problems (CASIO, 2016).

One of the operational problems is related to the reduction of demand in the morning (CASIO, 2016) with an increase in PV generation, and the sharp increase of demand in the afternoon due to the reduction in PV generation and the increase in residential loads. Although the wind generation also changes the load curve seen by the utilities, its variability and unpredictable generation shape, unlike solar generation, seems to lead to no iconic shape. Despite the fact that the wind generation also presents challenges to the system operator, the higher regularity and predictability of PV production rationally leads utilities to devise management strategies to mitigate some of the operational and business drawbacks thereof.

Jim Lazar (2016) proposes ten strategies to flatten the load shape, which reduce the amplitude of the ramping up and down periods. One of the strategies was named "Targeted Efficiency," which was regarding measures designed to provide savings in certain time periods. In order to properly design the measures, it is important to be aware of the load curve associated with the energy service requested by the customer. Besides the savings in energy, energy efficiency measures can significantly impact the demand curve, helping to defer investments in distribution and even in transmission grids (Nadel \& Herndon, 2014). These effects should not be ignored if the measures are to be properly valued.

Under the Tariff Code of the electricity sector, the Portuguese energy regulator (ERSE) developed a tender mechanism to promote energy efficiency on the customer side of the meter. It is a designated plan to promote the efficient use of electricity (PPEC), with a track record of six calls for proposals. This biennial tender mechanism is subject to an annual budget (funds come from electricity tariffs paid by all electricity consumers). The candidate measures must contribute to increasing awareness on energy efficiency and efficient behaviors, and to install equipment which reduces energy needs by utilizing higher efficiency or load management capabilities. It is expected that the implementation of these types of measures will also impact the electricity load diagrams.

Energy efficiency measures are long term by nature. In many regulatory settings, energy efficiency measures are assessed in prospective terms before decisions are made on their implementation, based on a few ex-ante, cost-benefit analyses (ICER, 2010; CPUC, 2001). In best practice examples, measurement and verification $(\mathrm{M} \& \mathrm{~V})$ protocols are included in the design of the energy efficiency measures in
Fig. 1 Load diagrams with "camel" and "duck" shapes

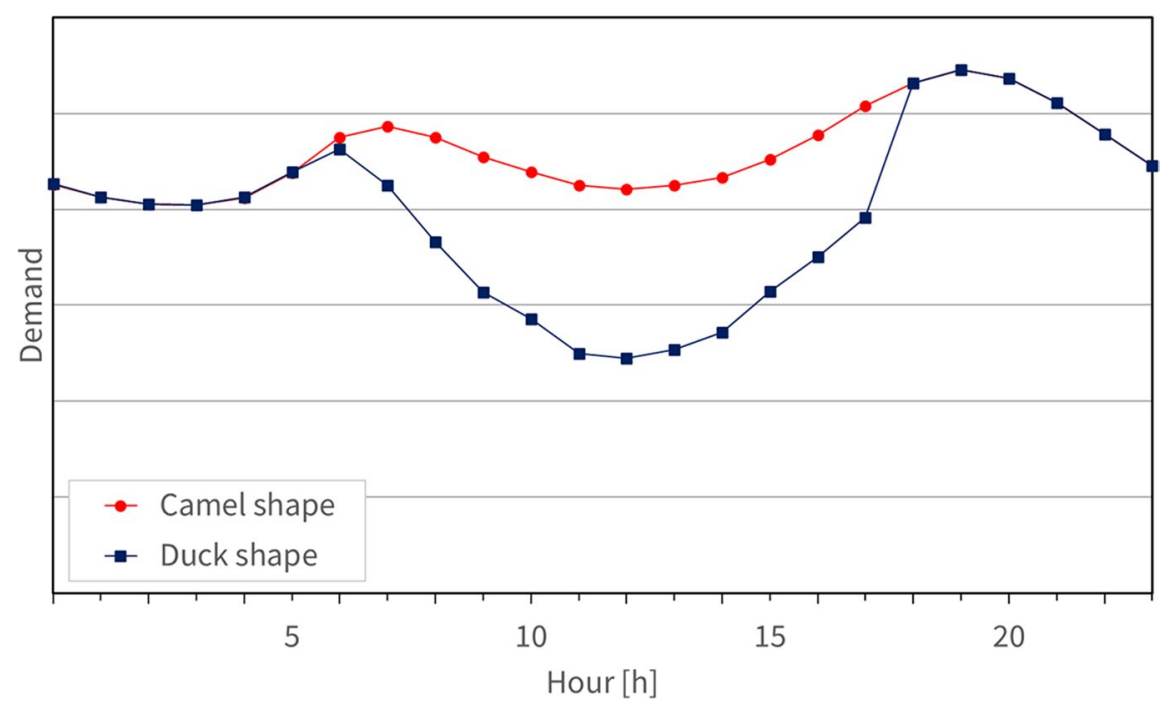


order to enable ex-post assessment of the measures' actual effects (National Plan for Energy Efficiency, 2008; RAP, 2012). These effects are directed at the long-term energy savings expected from the implementation of the measures, corresponding to the need to verify compliance with the design targets. Dynamic effects of the adoption of energy efficiency options by consumers, i.e., effects on load diagram shape, are usually not included in $\mathrm{M} \& \mathrm{~V}$ protocols. However, the effects of energy saving measures on the load diagram have long been identified in the framework of demand-side management (DSM) under the category of strategic conservation, along with having specific potential benefits for network planning and management (Nadel \& Herndon, 2014).

The main objective of this paper is to highlight the importance of estimating the effects of energy efficiency measures on load diagrams using the concept of load demand variations resulting from the implementation of the specified measures. This research employs the case study of the Portuguese PPEC mechanism for the residential sector. Real load diagrams of each end use addressed by the mentioned measures, resulting of two international programs, were used. Evidence is given to the fact that the possible inclusion of specific data collection on energy use in $\mathrm{M} \& \mathrm{~V}$ protocols of energy efficiency fostering programs will allow a focused detection of load diagram modification potential and more informed decisions on the attractiveness of certain measures.

In "Energy efficiency and load management actions: drivers, impacts and assessment," the literature review specifies the management of utilities regarding disruptive challenges, the impact of energy efficiency measures, and the assessment of load diagrams changes. The PPEC tender mechanism is presented in "Portuguese plan for the promotion of demand-side efficiency," along with the main results of this work. In "Estimating the impact of energy efficiency and load management measures on load diagram shape," the main steps of the developed methodology are described to estimate the diagrams of load variations. The estimation and presentation of the resulting diagrams of load variations for the case study follows in "Main results." In "Summary: The hidden impacts revealed by the DLV," an analysis is presented on the overall effect of the approved measures on the diagram of load variation. In
"Conclusions and policy implications," conclusions and policy implications are presented.

\section{Energy efficiency and load management actions: drivers, impacts, and assessment}

Although the main focus is the impact on energy demand or on emissions, energy efficiency measures have multiple benefits. The International Energy Agency (IEA, 2014) groups the multiple benefits into five categories: enhancing the sustainability of the energy system, economic development, social development, environmental sustainability, and increasing prosperity. Besides energy savings and greenhouse gas emissions, other benefits that were identified by the IEA are energy security, energy delivery, energy prices, macroeconomic impacts, industrial productivity, poverty alleviation, health and well-being, employment, local air pollution, resource management, public budgets, disposable income, and asset values. Regarding energy delivery impacts of energy efficiency, a few can be highlighted, such as improving system, reliability enhancing, capacity adequacy, improve peak management, better utilization of generation and other network assets, creating opportunities to defer investment in electric system assets, and dampening price volatility in wholesale market. The reduction of energy generation costs, the deferment of investments in grids infrastructure and reduction of line losses are some of the direct benefits of energy efficiency and load management measures to electric utilities. These measures can impact the transmission and the distribution grids, along with the system as a whole. However, its impact can be mostly useful, as a grid resource, if energy efficiency measures are used to address problems in some specific parts of the system, referred to as target efficiency measures or geo-targeting efficiency measures (Neme \& Grevatt, 2015). For example, with the replacement of light bulbs with new and more efficient light bulbs, savings could be obtained every time lights were on, but greater savings could be obtained in the evening hours of winter days, thus contributing to a reduction of the peak load. Utilities seek to implement the measures, which are in line with their objectives. For instance, they may implement a set of programs with measures targeting different end uses, depending on 
the objectives that they want to achieve. Neme \& Grevatt (2015) present several case studies, where the concept of geographically targeted efficiency programs was used to defer investments on the grids.

Crossley (2010) mentions that although energy efficiency measures intend to reduce consumption of the energy service, they can also reduce demand at the time of the system peak if the energy service contributes to the peak. However, energy efficiency measures are seldom implemented as a grid resource, as it is difficult for these measures to be accurate enough to provide operational network services. For these projects to be effective in achieving the objectives, they must be very clear, along with the targets (specific loads, end uses, and customer types). Some case studies are presented by Crossley (2010) where the purpose of the projects was mainly to defer network expansion. The focus of the presented projects was to overcome network and generation capacity limitations. Mostly, the objectives behind the implementation of those projects were overall load reductions and peak load reductions; some of the DSM measure addressed were energy efficiency, standby generation, distributed generation, cogeneration, pricing initiatives, direct load control, and interruptible loads. The presented projects were from the USA, Canada, India, Spain, France, Poland, UK, and Australia.

Gellings (2017) implies that the Annual Energy Outlook estimates that energy efficiency measures, such as efficient air conditioning, efficient space heating (heat pump), efficient water heaters (heat pump water heaters), efficient appliances, and efficient lighting, can reduce the summer peak by $79 \mathrm{GW}$ to $117 \mathrm{GW}$.

Although not a very common strategy, there are several examples around the world which depict that energy efficiency measures can help overcome constraints in electric grids (Crossley, 2010; Neme \& Grevatt, 2015).

Moreover, in a few jurisdictions, utilities are under the obligation of achieving targets of energy savings improving energy efficiency in consumption. In European countries, these obligations are commonly addressed as Energy Efficiency Obligations, while in the USA, they are known as Energy Efficiency Resource Standards (Sousa et al., 2013a). Utilities can, therefore, fulfill these obligations, all the while improving load profiles and trying to overcome constraints in the grid area.
The pressure to deploy distributed energy resources on the grids has been posing new challenges to network operators.

Energy policies, markets, and environmental concerns have been fostering the share of renewable energy sources in electricity production (Kind, 2013, Anvari, et al., 2016). In response to the need of reduction of emissions and the dependence from third parties, energy policies have been fostering the deployment of renewable local energy sources. Among the available renewable energy sources, wind power and photovoltaic (PV) have been receiving the most attention.

Moura \& Almeida (2010) studied the impact of measures, such as the replacement of inefficient appliances (refrigerators, freezers, lighting bulbs, air conditioners, traffic and public lights, and motors) with more efficient appliances to overcome problems which result from wind generation intermittence during peak load hours. For a period of 10 years, the impact of the replacement was estimated using load diagrams. A yearly consumption growth rate of $3 \%$ and an implementation of DSM measures corresponding to a reduction in consumption of $1 \% /$ year was measured.

With respect to PV, the availability of the source associated to decreasing investment costs, market availability, and technological improvements are the main reasons for the emerging interest in urban PV (Biyik et al., 2017). The increase in the share of PV associated to its intermittent nature presents important challenges to assure the reliability of the grid, which was not designed to incorporate high percentages of variable generation (Taar, 2018). The ability of the energy system to cope with this variability, commonly referred to as flexibility (Deason, 2018), is one of the most important future challenges.

Freitas \& Brito (2019) review several works which studied the use of PV orientations to serve as a resource to better match the grid load profile instead of looking for the maximization of the annual solar electricity production. Sousa et al. (2019) compared the impact of South (from the northern hemisphere) and West orientation of PV solar panels, in load diagrams from three different substations of the city of Coimbra, located in Portugal. It was found that Westfacing panels do not seem to contribute to smoothen the evening load gradient caused by the unavailability of solar generation at that time of the day. Other 
authors studied the impact of non-south (from the northern hemisphere) orientation of panels (Majzoobi \& Khodaei, 2016; Doroshenko et al., 2018; Borland \& Singh, 2018).

Apart from addressing the effect of the orientation of PV panels on the shape of the load diagram, distributed PV generation impact was also assessed from other perspectives, mainly on prices and bills, and how tariffs can help to minimize PV effects. Johnson et al. (2017) studied the impact of solar PV on electricity costs and bills. Although the increase in bills of non-participants (customers who do not install PV systems) is considered small (up to $2 \%$ ), there is a transfer of costs from customers who install PV systems to non-participants. Consequently, the authors also suggest that the reduction of the daily peak, due to the production of solar PV, shows the relative increase in the evening peak. This situation leads to an increase of the residential class rates, since they contribute more to the demand during the peak. Tariff changes are necessary in order to avoid the effect of the increasing number of consumers with PV systems, leaving the most disadvantaged consumers who are subject to rising electricity bills. Denholm et al. (2015) consider that time-of-use (TOU) pricing with fixed price intervals will not be adequate to address the mismatch between solar production and consumption. Torabi et al. (2018) also consider that TOU rates will not be able to manage the high shares of PV and wind production in island of Porto Santo, Portugal. According to their study, demand-side management measures, storage, and generation curtailment may be useful resources to manage the timing imbalance between generations from renewable sources, mainly PV and peak demand. Similar results were obtained by Qingchun Hou et al. (2019) for the Qinghai Province, China, where flexible resources, such as the retrofitting of coal-fired generation units, storage, PV curtailment, and demand response, would allow increasing shares of PV generation.

Some regulators or DSM program administrators in the USA use practical approaches to estimate the impact of the adoption of energy savings measures specifically on the peak load, aiming at the eversought reduction of maximum demand. The Retail/ Residential Technical Reference Manual of the Efficiency Maine Trust (2020) sets the procedures for the calculation of energy and demand savings of energy efficiency measures. For some measures, deemed saving values are provided. These deemed saving values may be obtained by direct evaluation, from the result of a research study or the result of deemed saving algorithms. Coincidence factors are also used in order to estimate demand saving during peak hours. The California Municipal Utilities Association (2017) also uses coincidence demand factors (CDF) to estimate demand reduction of lighting measures and other end uses during peak hours. For lighting measures, the CDF depend on the climate zone and the building type. Apart from CDF, other factors are used in the estimation process, such as heating, ventilation, air conditioning systems (HVAC) interactive effects, and the operating hours. The HVAC interactive effects tend to express the reduction of heat gains due to improved efficiency of the lighting technologies. Efficiency Vermont uses the Societal Cost Test of the California Standard Practice manual, as a primary cost-effectiveness test (Efficiency Vermont, 2018). They also use deemed values and coincidence factors to estimate demand reductions during peak hours.

\section{Portuguese plan for the promotion of demand-side efficiency}

The Portuguese energy regulator (ERSE) developed a tender mechanism, an actual market transformation (York et al., 2017) instrument, to promote energy efficiency in electricity consumption (PPEC). The first edition was published in 2007, and the program has a track record of six calls for proposals. At the time of the development of the presented work, the results from the last three editions were not yet known, and therefore, they were not included. This tender mechanism is funded by an annual budget, sourced from electricity tariffs paid by all electricity consumers. The selected measures must contribute to increased efficiency in electricity end use or be classified as load management (LM) actions. Former demand-side management plans were mandatory to the electricity distributors, but the participation in PPEC is now voluntary (Sousa et al., 2013b). Eligible promoters are electricity suppliers, network operators, consumer organizations, business associations, energy agencies, municipal associations, higher education institutions, and science research centers.

The candidate measures are classified as tangible (hard) and intangible (soft) measures. The tangible 
measures must propose the installation of equipment having energy efficiency levels above the market standard, or devices that allow/facilitate load management actions. On the other hand, measures, such as training courses, information disclosure campaigns, and energy audits, which are related to the disclosure of information regarding efficient use of electricity, are classified as intangible measures.

PPEC's annual budget amounts to 11.5 million Euros divided between the six tenders (Table 1). The financial incentive is divided among consumer segments, ensuring that all segments can receive incentives from PPEC. From 2009, the call for proposals became biennial and the budget amounts to 23 million euros.

By comparing the budget amounts for each PPEC edition (Table 1) with the total costs of eligible measures (Table 2), it is possible to see the high level of participation to the editions of this mechanism.

Every measure proposed to this tender has to be accompanied by a measurement and verification $(\mathrm{M} \& \mathrm{~V})$ plan. After implementation, the $\mathrm{M} \& \mathrm{~V}$ plan is followed to assess the performance and the results of the measure. Difficulties found during the implementation of the measures and the solutions adopted to overcome them are also reported. These M\&V plans are submitted to ERSE which compares the reported results with those determined by the adopted standard when the proposals were evaluated. At the end of this analysis, a decision is made on the most appropriate value to be credited as savings of the implemented measure. This analysis is performed for each measure, comparing the values adopted by the ERSE at the time of evaluation of the applications, the amounts of the $M \& V$ plan submitted to ERSE, and the results of applying ERSE standards to the values measured in the $M \& V$ plan. Finally, the most credible values are adopted for the purpose of accounting for the savings provided by each measure (ERSE, 2014a; b).

To the best of the authors' knowledge, only the results of PPEC editions of 2007, 2008, and 2009-2010 were fully published. Therefore, the savings figures registered after the $\mathrm{M} \& \mathrm{~V}$ plan will also be presented for these three PPEC editions, along with the estimated values. Table 3 illustrates the annual avoided consumption values of selected measures for the residential segment, for each PPEC edition. The avoided consumption measured after the implementation of the 2007 edition was more than $30 \%$ above the estimated value, reaching $40 \%$ for the 2008 edition and $28 \%$ for the 2009-2010 edition. In the residential sector, avoided consumption was

Table 1 Expected budget amounts for each PPEC edition (millions of euros) divided by tender, type of measures and consumer segment (ERSE, 2007a; ERSE, 2007b; ERSE, 2009; ERSE, 2010; ERSE, 2013; ERSE, 2016a)

\begin{tabular}{|c|c|c|c|c|c|c|}
\hline Tender and measure type / PPEC edition & 2007 & 2008 & 2009-2010 & 2011-2012 & 2013-2014 & 2017-2018 \\
\hline Intangible measures (all promoters) & 2.0 & 2.0 & 3.5 & 3.5 & 3.0 & 2.0 \\
\hline \multicolumn{7}{|l|}{ Tangible measures (all promoters) } \\
\hline - Industry and agriculture & 3.0 & 3.0 & 5.8 & 5.8 & 5.1 & 7.0 \\
\hline - Commerce and services & 2.5 & 2.5 & 4.9 & 4.9 & 4.3 & 4.0 \\
\hline - Residential & 2.5 & 2.5 & 5.3 & 5.3 & 4.6 & 3.0 \\
\hline Intangible measures (non-electricity sector companies) & - & - & 1.5 & 1.5 & 3.0 & 3.0 \\
\hline Tangible measures (non-electricity sector companies) & - & - & 2.0 & 2.0 & 3.0 & 4.0 \\
\hline Total & 10.0 & 10.0 & 23.0 & 23.0 & 23.0 & 23.0 \\
\hline
\end{tabular}

Table 2 Costs of the eligible candidate measures to each PPEC edition (in millions of euros) (ERSE, 2007a; ERSE, 2007b; ERSE, 2009; ERSE, 2010; ERSE, 2013; ERSE, 2016b)

\begin{tabular}{lrrrrrr}
\hline Measure type/ PPEC edition & 2007 & 2008 & $2009-2010$ & $2011-2012$ & $2013-2014$ & $2017-2018$ \\
\hline Intangible measures & 7.3 & 8.7 & 18.3 & 18.3 & 28.2 & 24.6 \\
Tangible measures & 19.3 & 37.5 & 39.8 & 38.8 & 30.6 & 37.3 \\
Total & 26.6 & 46.3 & 58.1 & 57.1 & 58.8 & 61.9 \\
\hline
\end{tabular}


Table 3 Annual avoided consumption of all selected tangible measures and for the measures for the residential sector (ERSE, 2007a; b; ERSE, 2009; ERSE, 2010; ERSE, 2013; ERSE, 2016b; ERSE, 2011; ERSE, 2014a; ERSE, 2017b)

\begin{tabular}{lll}
\hline PPEC edition & $\begin{array}{l}\text { Annual Avoided con- } \\
\text { sumption (MWh/yr) }\end{array}$ & $\begin{array}{l}\text { Annual Avoided } \\
\text { consumption in the } \\
\text { residential }(\mathrm{MWh} / \mathrm{yr})\end{array}$ \\
\hline 2007 & $49129\left(64654^{(\mathrm{a})}\right)$ & $24536\left(44_{\left.100^{(\mathrm{a})}\right)}\right.$ \\
2008 & $83116\left(117168^{(\mathrm{a})}\right)$ & $37018\left(55064^{(\mathrm{a})}\right)$ \\
$2009-2010$ & $363595\left(464874^{(\mathrm{a})}\right)$ & $86312\left(77718^{(\mathrm{a})}\right)$ \\
$2011-2012$ & 202704 & 43646 \\
$2013-2014$ & 159530 & 18528 \\
$2017-2018$ & 102622 & 14687 \\
\hline
\end{tabular}

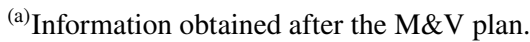

nearly $80 \%$ above the 2007 estimated values, almost $50 \%$ above the estimated value of the 2008 edition and $10 \%$ below the estimated value of the 2009-2010 edition of PPEC.

\section{Estimating the impact of energy efficiency and load management measures on load diagram shape}

Energy efficiency measures are evaluated using a set of criteria, including avoided consumption. According to the usual approaches to the cost-benefit assessment of DSM programs, estimations of the changes on the load diagram of energy efficiency measures are not required for evaluation purposes. This is also verified in the PPEC case study. Nevertheless, changes in the load diagrams will impact the energy costs, the costs of supplying each $\mathrm{kWh}$, and the utility's revenues, along with affecting the available capacity of the electric system infrastructures and its capacity reinforcement plans.

\section{Diagrams of load variation}

From the DSO point of view, the impact of energy efficiency and LM measures is beyond the avoided $\mathrm{kWh}$ due to energy savings by consumers. In some cases, the replacement of end-use equipment with more energy-efficient alternatives may not cause any changes in usage patterns, having no influence on the load profile, other than the power demand values. The same does not occur when different technologies are used for the same energy service or when load management measures are implemented, which will directly change load diagram shapes.

Since the load diagrams regarding each measure and the corresponding technology were not estimated nor measured under the PPEC procedures by any other means, the authors developed the concept of diagrams of load variations (DLV) to estimate the changes caused in load diagrams by the implementation of energy efficiency and LM measures. It corresponds to a generalized assessment of load curve impacts which may serve the purpose of supporting decisions on the implementation of each energy efficiency measure under consideration, for any strategies of load curve modification, including (but not restricted to) influencing peak demand. The measures addressing the residential sector selected to be implemented through the PPEC editions are used as a case study.

Data from two residential energy consumption characterisation studies were used to estimate the DLV, Residential Monitoring to Decrease Energy Use and Carbon Emissions in Europe (REMODECE) (ISR-UC, 2008), and EURECO, a European SAVE project (CEC, 2002). In the next two sections, the developed methodologies for the estimations of load variations due to energy efficiency measures and LM measures are presented.

\section{DLV of energy efficiency measures}

For the estimation of DLV from energy efficiency measures, data from the REMODECE project were used, mainly for the estimation of the Consumption Correction Factors (CCF) and of load diagrams for working and weekend days (2nd and 4th steps described in the present section). The CCF will allow the estimation of electric energy consumption for work and weekend days.

The steps followed to estimate DLV due to energy efficiency measures are as follows:

Step 1. Estimation of the Average Daily Avoided Consumption: the average daily avoided consumption $\left(A C_{\text {day }}\right)(1)$ of each measure was calculated based on the annual avoided consumption $\left(A C_{y r}\right)$ estimation, the number of devices ( $n)$, and the number of days of use of the proposed technology in the year (days). 


$$
A C_{\text {day }}=\frac{A C_{\mathrm{yr}}}{n \cdot \text { days }}
$$

Step 2. Estimation of the Consumption Correction Factors (CCF): the CCF will allow to obtain estimations of consumption values for working $\left(A C_{\text {work }}\right)$ and weekend $\left(A C_{\text {weekend }}\right)$ days. With the $\mathrm{CCF}$ for working $\left(\mathrm{CCF}_{\text {work }}\right)$ and for weekend $\left(\mathrm{CCF}_{\text {weekend }}\right)$ days, it will be possible to estimate the consumption values knowing the average daily consumption value $\left(A C_{\text {day }}\right)$. The CCF will be calculated using data from REMODECE and then applied to the $A C_{\text {day }}$ to obtain the corresponding values for working and weekend days for the measures funded by PPEC. Load diagrams from the REMODECE project were used to estimate daily avoided consumption values, for both categories. In the REMODECE project, load diagrams for a set of energy services were also estimated for both categories. The $C_{\text {work }}$ and $C_{\text {weekend }}$ consumption values were calculated based on the corresponding daily load diagrams. Taking the number of working (days ${ }_{\text {work }}$ ) and weekend days (days weekend ) in a year, $C_{\text {day }}$ was estimated (2). The $\mathrm{CCF}$ for working days results from dividing $C_{\text {work }}$ by $C_{\text {day }}$ (3). The same procedure was used to estimate the CCF for weekend days.

Step 3. Estimation of the average daily avoided consumption values for working $\left(A C_{\text {work }}\right)$ and weekend $\left(A C_{\text {weekend }}\right)$ days: With the computed $\mathrm{CCF}$ for working days and the average daily avoided electricity consumption estimated for PPEC measures, the $A C_{\text {work }}$ for each PPEC measure was estimated (4). Identical procedure was used to estimate the $A C_{\text {weekend }}$.

$C_{\text {day }}=\left(C_{\text {work }} \cdot\right.$ days $_{\text {work }}+C_{\text {weekend }} \cdot$ days $\left._{\text {weekend }}\right) / 365$

$\mathrm{CCF}_{\text {work }}=\frac{C_{\text {work }}}{C_{\text {day }}}$

Step 4. Estimation of the Average daily avoided consumption values for working $\left(A C_{\text {work }}\right)$ and weekend $\left(A C_{\text {weekend }}\right)$ days: With the computed $\mathrm{CCF}$ for working days and the average daily avoided electricity consumption estimated for PPEC measures, the $A C_{\text {work }}$ for each PPEC measure was estimated (4). Identical procedure was used to estimate the $A C_{\text {weekend }}$.
$A C_{\text {work }}=\mathrm{CCF}_{\mathrm{work}} \cdot A C_{\text {day }}$

Step 5. Load profiles estimation: The load profiles, both for working and weekend days, of each energy service/technology, were obtained dividing the hourly energy consumption values, numerically equal to the average power demand values expressed in $\mathrm{kW}, P(t)$, of the load diagram (from REMODECE) by the corresponding daily consumption values numerically equal to the sum of the hourly average power demand values, if expressed in $\mathrm{kW}(5)$. A load profile $(L P)$ is, thus, equivalent to a load diagram of one $\mathrm{kWh}$ daily consumption.

$L P(t)=\frac{\int_{t-1}^{t} P(t) d t}{\int_{0}^{24} P(t) d t}$

Step 6. Average daily diagrams of load variations estimation: the average daily DLV, for working and weekend days, results from the product of each hourly value of the load profile by the estimated average daily avoided consumption values, for working $\left(A C_{\text {work }}\right)$ and weekend $\left(A C_{\text {weekend }}\right)$ days. Equation (6) shows the calculation of the hourly values of the DLV for working days, $\mathrm{DLV}_{\text {work }}(t)$. Identical procedure was used to calculate the hourly values of the DLV for weekend days, $\operatorname{DLV}_{\text {weekend }}(t)$.

$\operatorname{DLV}_{\text {work }}(t)=L P(t) \cdot A C_{\text {work }}$

Step 7. Diagrams of load variations estimation for a measure: the estimation of the diagrams of load variations for the whole set of devices replaced/distributed by the measure are obtained by multiplying each hourly value of the DLV by the number of devices (n).

\section{DLV of load management measures}

The load management measures approved by PPEC were aimed at the reduction of standby power of electric appliances or devices.

In order to estimate the DLV resulting from these measures, the standby power load diagrams obtained under the EURECO project were used. Since EURECO estimated daily load diagrams for each equipment/energy service, not distinguishing working from weekend days, the estimation of the CCFs was rendered useless. 
To estimate the LM DLV, the steps presented in "DLV of energy efficiency measures" should be followed, except for the estimation and use of the CCFs $\left(2^{\text {nd }}\right.$ to $4^{\text {th }}$ steps $)$.

\section{Main results}

The analysis was done by defining six major types of measures: four distinct energy services (lighting, refrigeration and freezing, water heating, and air conditioning), load management, and information related measures. Measures were considered as load management measures when they impose the installation of any device which allows for behavioral changes, leading to some modification of the load diagram. Information-related measures are based on the installation of devices which provide information on consumption, helping decision making by consumers, regarding the energy services they use.

Measures addressing lighting technology replacement were the most common type of measures approved and selected in all PPEC editions in the residential sector. Lighting technology selected measures altogether represent $59 \%$ of the total number of measures and $84 \%$ of the annual avoided consumption. The number of measures of each type for all PPEC editions can be seen in Table 4.

In the following sections, each type of measure will be analyzed and the corresponding DLV estimated. Due to the lack of data, it was not possible to estimate the impact of the air conditioning measure on the load diagram.
Lighting

PPEC funds should be used to overcome market barriers. Until the 2011/2012 edition, efficiency class "C" improved incandescent bulbs were considered the market standard for lighting technology for the residential sector, and nearly all measures addressing lighting technologies proposed the replacement of incandescent with compact fluorescent light (CFL) bulbs. After 2011/2012, considering that the market barrier to the introduction of CFL was overcome, CFL became the market standard technology. Since then, measures addressing this technology are heavily penalized. LED technology became the most common lighting technology proposed, mainly for the replacement of halogen dichroic lamps and the measures which promote them were valued.

In Table 5, the number of lighting technology replacement measures, the corresponding avoided consumption, the number of promoters, and the adopted technology for all PPEC editions are presented, along with the implementation results for the PPEC editions of 2007, 2008, and 2009-2010. In these cases, the verified avoided consumption values were higher than the approved values: around $82 \%$ higher for the 2007 edition and 51\% for the 2008 edition. For the 2009-2010 edition, the verified avoided consumption value was $10 \%$ lower than the approved value.

Regarding the 2007 edition, the avoided consumption values higher than the estimated values were mainly due to two measures which distributed more than 1.6 times the approved number of lamps. The resulting increase in costs of one of the measures was supported by the promoter and the participating customers. The promoter of the other measure was able
Table 4 Number of measures approved for the residential sector in all PPEC editions and related avoided consumption, by type of measure

\begin{tabular}{lllcl}
\hline Type of measures & $\begin{array}{l}\text { Number of } \\
\text { measures }\end{array}$ & $\begin{array}{l}\text { Number of } \\
\text { Measures (\%) }\end{array}$ & $\begin{array}{l}\text { Annual avoided con- } \\
\text { sumption (GWh/yr) }\end{array}$ & $\begin{array}{l}\text { Annual avoided } \\
\text { consumption } \\
(\%)\end{array}$ \\
\hline Lighting & 23 & $59 \%$ & 221.86 & $84 \%$ \\
Refrigeration and freezing & 3 & $8 \%$ & 2.81 & $1 \%$ \\
Water heating & 4 & $10 \%$ & 4.48 & $2 \%$ \\
Air conditioning & 1 & $2 \%$ & 1.28 & $0 \%$ \\
Load management & 5 & $13 \%$ & 17.16 & $7 \%$ \\
Information & 3 & $8 \%$ & 14.63 & $6 \%$ \\
Total & 39 & $100 \%$ & 262.22 & $100 \%$ \\
\hline
\end{tabular}


Table 5 Number of measures and avoided consumption of measures addressing lighting, in each PPEC edition

\begin{tabular}{lllll}
\hline PPEC edition & $\begin{array}{l}\text { Number of meas- } \\
\text { ures }\end{array}$ & $\begin{array}{l}\text { Annual avoided consump- } \\
\text { tion }(\mathrm{GWh} / \mathrm{yr})\end{array}$ & $\begin{array}{l}\text { Number of promot- } \\
\text { ers }\end{array}$ & $\begin{array}{l}\text { Technology } \\
2007\end{array}$ \\
2008 & 4 & $23.99\left(43.54^{(\mathrm{a})}\right)$ & 3 & CFL \\
$2009 / 2010$ & 6 & $34.34\left(52.42^{(\mathrm{a})}\right)$ & 3 & CFL \\
$2011 / 2012^{(\mathrm{b})}$ & 4 & $85.38\left(77.72^{(\mathrm{a})}\right)$ & 6 & CFL \\
$2013 / 2014$ & 2 & 26.65 & 4 & CFL, LED, and occupancy sensors \\
$2017 / 2018$ & 4 & 6.53 & 1 & LED \\
Total & 23 & 6.00 & 3 & LED and occupancy sensors \\
\hline
\end{tabular}

${ }^{(a)}$ Information obtained after the M\&V plan.

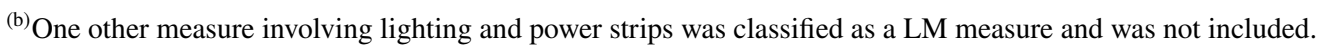

${ }^{(c)}$ Number of different promoters.

to obtain a reduction of $60 \%$ of the unit price of the lamps, allowing them to distribute more lamps using the same amount of funding (ERSE, 2007a; ERSE, 2011).

The higher avoided consumption values verified for the 2008 edition were also mostly due to the increase in the number of distributed lamps and the verified number of hours of use. This was the case of three of the measures. The verified avoided consumption of the other measure was lower than the expected. The promoter distributed discount vouchers ( $€ 1.50$ each) for the purchase of CFLs in exchange for an incandescent lamp, and the reduced number of reimbursed discount vouchers (less than $2 / 3$ of the expected) became the main reason for the lower-than expected savings (ERSE, 2007b; ERSE, 2014a).

The 2009/2010 PPEC edition approved lighting technology replacement measures, also involving more promoters (ERSE, 2009). Moreover, the annual avoided consumption was almost twice the promoted in previous editions, considering that this was a biennial edition, while the former editions were not.

Four lighting measures were approved under the 2011/2012 edition. One of the measures aimed to install 10,000 occupancy sensors inside elevator's cabins. Another measure intended to distribute CFLs, while the other two promoted the replacement of incandescent (halogen and tungsten) lamps by LED lamps (ERSE, 2010). Both approved measures in the 2013/2014 PPEC edition, which aimed at the replacement of halogen dichroic lamps by LED lamps. One of the measures consisted of the development of a software tool which should be able to deliver a report based on the consumers lighting systems and corresponding use profile (ERSE, 2013).

The 2017/2018 edition approved four lighting measures. Three of the measures aimed to replace incandescent, halogen dichroic, and CFL lamps for LED lamps in social habitations and buildings, replacing a total of 202,372 lamps. The fourth measure intended to install 1500 lighting control systems in elevators using occupancy sensors (ERSE, 2016a).

Since we are approaching technology replacement, no other change was expected than a reduction of the power demand level. The estimation of the DLV was based on the load diagrams estimated under the REMODECE project (see "Diagrams of load variation"). Under REMODECE project, lighting load diagrams were estimated based on data monitored in living rooms and secondary rooms. The overall load diagram was estimated on the assumption of four lamps in the living room and 13 in secondary rooms. The resulting load diagram was used to obtain the lighting load profile. Using this load profile and the estimation of the daily avoided consumption of each measure, DLV were obtained, as presented in "Diagrams of load variation."

Figure 2 presents the cumulative effect of the estimated daily DLV, for lighting in working days of each PPEC edition. Although some of the funded equipment reaches their expected useful life with time, it was considered that the customer would replace it with another equipment of equivalent or higher energy efficiency level. It is then possible to obtain the total DLV as the sum of the contributions 


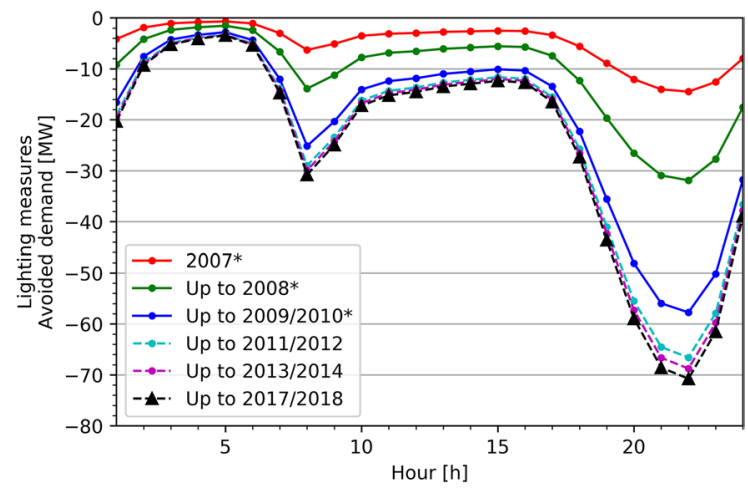

Fig. 2 Daily DLV, for working days, for each PPEC edition, and the total resulting variation of all the measures addressing lighting technology replacement

of all the measures, regardless of the time span between them.

The 2011/2012 measure, which proposed the installation of 10,000 occupancy sensors inside elevator cabins, was not included, since no elevators lighting load diagram was found in the literature. The annual avoided consumption of this measure represented around 3\% of the total annual avoided consumption in lighting for all PPEC editions.

The costs of each saved $\mathrm{kW}$ at peak $\left(\mathrm{CSkW}_{\text {peak }}\right)$ for the approved measures to improve efficiency in lighting, in each PPEC edition are presented in Table 6. The $\mathrm{CSkW}_{\text {peak }}$ was obtained by the ratio between the summed costs of all measures of the same type and the total demand reduction at peak time.
The saved $\mathrm{kW}$ at peak lasts the lifetime of each measure. The technology involved in improving energy efficiency in lighting has an expected lifetime between 6 and 20 years. For instance, the lifetime of the technology promoted in 2007 PPEC edition was 6 years, while in the 2013/2014 PPEC edition, it lasts 20 years. Although some of the funded equipment already ended its expected lifetime, the investment made was considered as the cost of overcoming the market barrier.

Without accounting for any other advantage and considering the promotion of energy efficiency measures as a strategy to address capacity constraints, the $\mathrm{CSkW}_{\text {peak }}$ corresponds to the cost of avoiding the increase of one $\mathrm{kW}$ of peak. For example, in the case of the 2013/2014 measures, it amounts to $723.01 € /$ $\mathrm{kW}_{\text {peak }}$ and should last 20 years.

\section{Refrigeration and freezing}

Refrigeration and freezing were the residential energy service with the second highest avoided energy consumption, despite being at a considerable distance from the first. Overall, only three measures for this energy service were approved, in three different PPEC editions (Tables 4 and 7).

Under the 2007 PPEC edition, the approved measure proposed the replacement of refrigerators by some belonging to energy efficiency class A.

In 2008, the approved measure aimed the replacement of freezers by class A ones. Due to implementation difficulties, financial support was also given to

Table 6 The costs of each saved $\mathrm{kW}$ at peak $\left(\mathrm{CSkW}_{\text {peak }}\right)$ for the approved measures to improve efficiency in lighting, in each PPEC edition

\begin{tabular}{lllllll}
\hline Edition & 2007 & 2008 & $2009 / 2010$ & $2011 / 2012$ & $2013 / 2014$ & $2017 / 2018$ \\
$\mathrm{CSkW}_{\text {peak }}\left(€ / \mathrm{kW}_{\text {peak }}\right)$ & $146.92^{(\mathrm{a})}$ & $118.07^{(\mathrm{a})}$ & $104.96^{(\mathrm{a})}$ & 251.64 & 723.01 & 340.95 \\
\hline
\end{tabular}

${ }^{(a)}$ Information obtained after the M\&V plan.

Table 7 Number and avoided consumption of measures addressing refrigeration and freezing, in each PPEC edition

\begin{tabular}{lllll}
\hline PPEC edition & $\begin{array}{l}\text { Number of } \\
\text { measures }\end{array}$ & $\begin{array}{l}\text { Annual avoided con- } \\
\text { sumption }(\mathrm{GWh} / \mathrm{yr})\end{array}$ & $\begin{array}{l}\text { Number of } \\
\text { promoters }\end{array}$ & Technology \\
\hline 2007 & 1 & $0.55\left(0.55^{(\mathrm{a})}\right)$ & 1 & $\begin{array}{l}\text { Refrigerators } \\
\text { Refrigerators, freez- } \\
\text { ers and fridge } \\
\text { freezers }\end{array}$ \\
2008 & 1 & $1.03\left(1.05^{(\mathrm{a})}\right)$ & 1 & $\begin{array}{l}\text { Fridge freezers } \\
\text { Total }\end{array}$ \\
\hline
\end{tabular}


Table 8 Refrigeration and freezing appliances ownership rates (ISR-UC, 2008)

\begin{tabular}{llll}
\hline Appliance & Refrigerator & Freezer & Fridge freezers \\
\hline Ownership rate & $35 \%$ & $50 \%$ & $79 \%$ \\
\hline
\end{tabular}

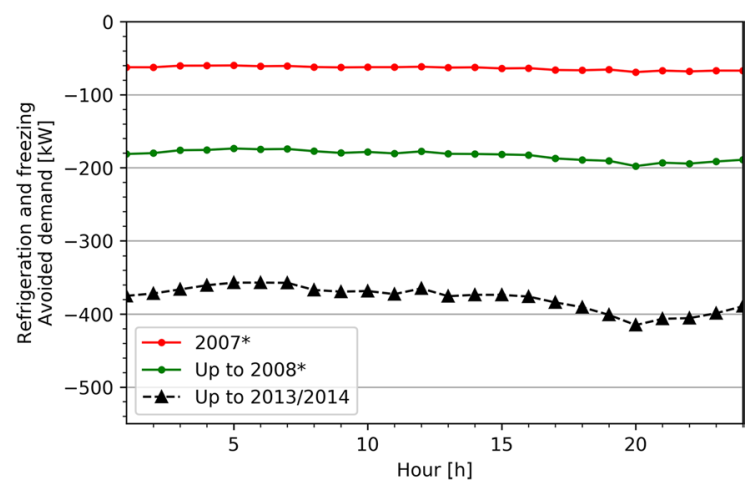

Fig. 3 Daily DLV, for working days, for each PPEC edition, of measures addressing refrigeration and freezing

the replacement of refrigerators and fridge freezers (ERSE, 2014a).

Under 2013/2014 PPEC edition, a rebate of 100 euros/unit was given to foster the replacement of $8000 \mathrm{~B}$ or $\mathrm{C}$ ratings fridge freezers by $\mathrm{A}+++$ ones (ERSE, 2014b). (a) Information obtained after M\&V plan.

(b) The number of different promoters.

The load profile of each energy service was estimated from the daily load diagrams obtained under the REMODECE project. The DLV of the 2007, 2008, and 2013/2014 PPEC editions were obtained following the ownership rate of each appliance, along with the REMODECE project (Table 8).

The daily DLV were estimated using the load profiles of each technology and the average avoided daily consumption of each measure (Fig. 3), knowing that each year diagram reflects the cumulative changes of the preceding years.

The $\mathrm{CSkW}_{\text {peak }}$ of the approved measures to improve energy efficiency in refrigeration and freezing are presented in Table 9. The saved $\mathrm{kW}$ of peak lasts the lifetime of each measure, which was considered to be 15 years for all the promoted technologies.

\section{Water heating}

For the last six PPEC editions, only four measures regarding water heating were approved (Table 10). One of the measures, from 2009/2010 PPEC edition, proposed the distribution of compact solar collectors to customers who own electric water heaters (EWH). The 2013/2014 PPEC edition approved

Table 9 The costs of each saved $\mathrm{kW}$ of peak $\left(\mathrm{CSkW}_{\text {peak }}\right)$ for the approved measures to improve efficiency in refrigeration and freezing, in each PPEC edition

\begin{tabular}{llll}
\hline PPEC edition & 2007 & 2008 & $2009-2010$ \\
$\mathrm{CSkW}_{\text {peak }}\left(€ / \mathrm{kW}_{\text {peak }}\right)$ & $3284.80^{(\mathrm{a})}$ & $2533.04^{(\mathrm{a})}$ & 3084.90 \\
\hline
\end{tabular}

${ }^{(a)}$ Information obtained after M\&V plan

Table 10 Number and avoided consumption of measures addressing water heating, in each PPEC edition

\begin{tabular}{llllc}
\hline PPEC edition & Number of measures & $\begin{array}{l}\text { Annual avoided consumption } \\
(\mathrm{GWh} / \mathrm{yr})\end{array}$ & Number of promoters & Technology \\
\hline $2009 / 2010$ & $1\left(0^{(\mathrm{a})}\right)$ & $1.01\left(0^{(\mathrm{a})}\right)$ & 1 & Solar panels \\
$2013 / 2014$ & 1 & 1.76 & 1 & Heat pumps \\
$2017 / 2018$ & 2 & 2.72 & 1 & $\begin{array}{c}\text { Heat pumps and } \\
\text { high efficiency } \\
\text { EWH }\end{array}$ \\
Total & 2 & & $1^{(\mathrm{b})}$ & - \\
\hline
\end{tabular}

${ }^{(a)}$ Information obtained after M\&V plan. This measure was not implemented

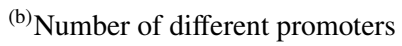




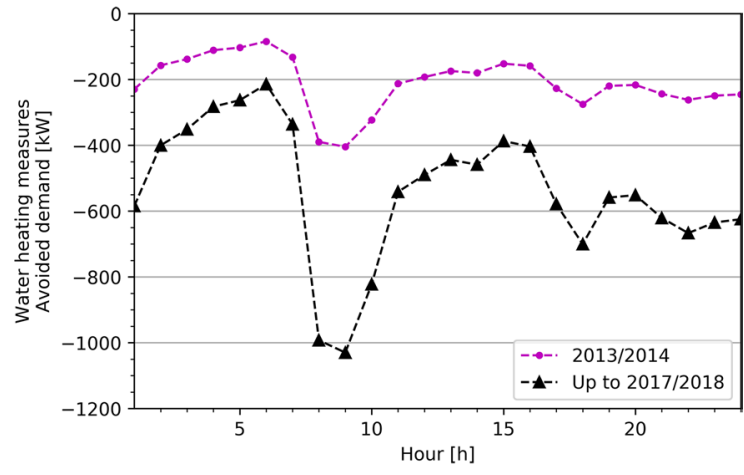

Fig. 4 Daily DLV, for working days, for each PPEC edition, regarding water heating energy service

measure promotes the replacement of EWH with heat pumps. This measure includes the distribution of water flow restrictors for use in taps and showers (ERSE, 2014b). In the 2017/2018 edition, the two approved measures proposed the replacement of conventional EWH by heat pumps and high efficiency EWH, enabling a more efficient use of energy for water heating in 2,500 dwellings (ERSE, 2017a).

The DLV (Fig. 4) were estimated based on REMODECE load diagrams for electric water heaters. Each diagram reflects the cumulative changes of the preceding PPEC measures.
The $\mathrm{CSkW}_{\text {peak }}$ of the approved measures to improve energy efficiency in water heaters are presented in Table 11. The $\mathrm{CSkW}_{\text {peak }}$ lasts 20 years, which is the expected lifetime of the involved technology (ERSE, 2013; ERSE, 2017a).

\section{Load management}

Load management measures are specifically directed at changing the shape of the load diagrams. Only five LM measures were approved in all six PPEC editions (Tables 4 and 12).

The 2008 measure intended to reduce the standby power associated with a few residential loads, namely entertainment audio-visual equipment. Under the approved measure, a power strip was to be distributed to customers who purchased a television set, a Hi-fi system, or a DVD player (ERSE, 2007b). However, due to the reduced adherence, a power strip was given to customers who bought any electric appliance. Furthermore, half of the power strips were distributed together with a CFL (ERSE, 2014a).

In 2011/2012 edition, two measures were approved. One of the measures (measure A) aimed at the distribution of a master/slave power strip, while the other measure (measure B) included a LED lamp to be distributed with a master/slave power strip. These master/slave power strips are

Table 11 The costs of each saved $\mathrm{kW}$ of peak $\left(\mathrm{CSkW}_{\text {peak }}\right)$ for the approved measures to improve efficiency in water heaters, in each PPEC edition

\begin{tabular}{llll}
\hline PPEC edition & $2009 / 2010$ & $2013 / 2014$ & $2017 / 2018$ \\
$\mathrm{CSkW}_{\text {peak }}\left(€ / \mathrm{kW}_{\text {peak }}\right)$ & $\left(0^{(\mathrm{a})}\right)$ & 988.92 & 1092.98 \\
\hline
\end{tabular}

${ }^{(a)}$ Information obtained after M\&V plan.

Table 12 Number and avoided consumption of load management measures, in each PPEC edition

\begin{tabular}{lllll}
\hline PPEC edition & $\begin{array}{l}\text { Number of meas- } \\
\text { ures }\end{array}$ & $\begin{array}{l}\text { Annual avoided consump- } \\
\text { tion }(\mathrm{GWh} / \mathrm{yr})\end{array}$ & $\begin{array}{l}\text { Number of pro- } \\
\text { moters }\end{array}$ & $\begin{array}{l}\text { Technology } \\
2008\end{array}$ \\
$2011 / 2012^{(\mathrm{b})}$ & 2 & $1.65\left(1.60^{(\mathrm{a})}\right)$ & 1 & Power strips with a master switch \\
$2013 / 2014$ & 1 & 5.62 & 1 & Master/slave power strips + LED lamps \\
$2017 / 2018$ & 1 & 5.26 & 1 & Master/slave power strips \\
Total & 5 & 4.68 & 1 & Master/slave power strips \\
\hline
\end{tabular}

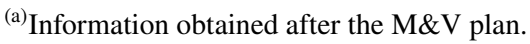

(b) Includes one measure involving lighting and power strips.

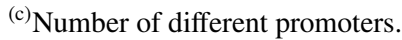


auto power off systems which react when an appliance is switched off by turning off all other equipment connected to the power strip. Some sets of appliances which are suitable to be connected to these power strips are entertainment audio-visual devices (television set, DVD player, Hi-Fi, and set top box), and office equipment (desktop and laptop computers, printers, internet routers, and wireless access points) (ERSE, 2010).

The measures approved in the 2013/2014 and 2017/2018 PPEC editions also intended the distribution of master/slave power strips, totalling for all editions a distribution of 382,000 new load management devices (ERSE, 2007b; ERSE, 2010; ERSE, 2013; ERSE, 2017a).

Standby power hourly curves used in this study were obtained under the EURECO project (CEC, 2002). The standby power load profiles were estimated and then used to obtain the DLV of standby power for each measure, following the steps presented in "DLV of energy efficiency measures."

In order to estimate the DLV, it is necessary to know which type or types of equipment were considered by the promoters while estimating avoided consumptions. For the 2008 edition measure, although only half the number of power strips was distributed with entertainment audio-visual equipment and the other half was distributed together with a CFL to who bought any electric appliance, the DLV was estimated considering only audio-visual equipment standby load profiles.

The estimation of avoided consumption due to measure A of the 2011/2012 edition assumed that the power strips were to be used with entertainment audio-visual equipment, as indicated by the promoter (EDPC, not dateda). On the other hand, avoided consumption estimations of measure B, for the same PPEC edition, assumed that half the number of distributed power strips were to be used with entertainment audio-visual equipment and the other half with office equipment (EDPC, not datedb). Avoided consumption estimation of the measures of the 2013/2014 and 2017/2018 editions were also based on the assumption that half the number of distributed power strips were to be used with entertainment audio-visual equipment and the other half with office equipment (EDPSU, not dated). For these three measures, the DLV were estimated respecting the assumptions considered by the promoters.
In Fig. 5, the DLV for the LM measures selected to be funded by PPEC are presented. As mentioned earlier, each curve includes the cumulative changes due to the measures from the preceding PPEC editions.

The $\mathrm{CSkW}_{\text {peak }}$ of the LM approved measures are presented in Table 13. The $\mathrm{CSkW}_{\text {peak }}$ lasts from eight to 16 years that are the expected lifetime periods of the involved technology.

\section{Information-related measures}

Regarding tangible information-related measures for the residential sector, only three measures were approved. These measures mainly promoted the installation of energy trackers. With energy trackers, the energy consumption data is displayed, and it is expected that it will help the consumer's decisionmaking process. Two types of electricity consumption meters were made available under the approved measures: device consumption meters and consumption meters for the whole dwelling. The latter type was distributed under 2011-2012 measures (ERSE, 2010), while the former type was distributed in 2013-2014 PPEC edition (ERSE, 2013). Overall, three measures were selected (Table 14).

The avoided consumption estimations of the 2013-2014 PPEC edition measure took the avoided consumption into account, which resulted from three actions: (1) the reduction of standby power of entertainment audio-visual appliances and office equipment, (2) the reduction of refrigeration and freezers consumption that resulted from the behavioral changes (reduction of door openings and cleaning the back of the appliance) and appropriate

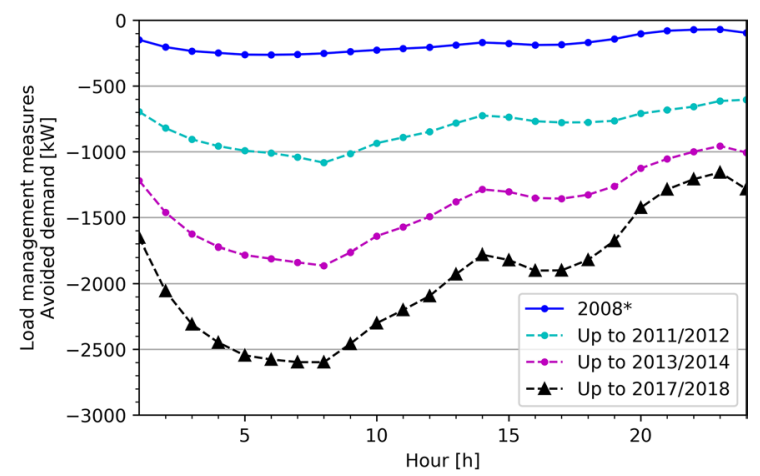

Fig. 5 Daily DLV, for working days, for each PPEC edition, regarding load management measures 
Table 13 The costs of each saved $\mathrm{kW}$ of peak $\left(\mathrm{CSkW}_{\text {peak }}\right)$ for the approved load management measures, in each PPEC edition

\begin{tabular}{lllll}
\hline PPEC edition & 2008 & $2011 / 2012$ & $2013 / 2014$ & $2017 / 2018$ \\
$\mathrm{CSkW}_{\text {peak }}\left(€ / \mathrm{kW}_{\text {peak }}\right)$ & $965.33^{(\mathrm{a})}$ & 1101.17 & 1891.24 & 887.98 \\
\hline
\end{tabular}

${ }^{(a)}$ Information obtained after the M\&V plan.

Table 14 Number and avoided consumption of information measures, in each PPEC edition

\begin{tabular}{lllll}
\hline PPEC edition & $\begin{array}{l}\text { Number of } \\
\text { measures }\end{array}$ & $\begin{array}{l}\text { Annual avoided con- } \\
\text { sumption }(\mathrm{GWh} / \mathrm{yr})\end{array}$ & $\begin{array}{l}\text { Number of } \\
\text { promoters }\end{array}$ & Technology \\
\hline $2011 / 2012$ & 2 & 13.37 & 2 & $\begin{array}{l}\text { Consumption meters for the } \\
\text { whole dwelling }\end{array}$ \\
$2013 / 2014$ & 1 & 3.26 & 1 & $\begin{array}{l}\text { Device Consumption meters } \\
\text { Total }\end{array}$ \\
\hline
\end{tabular}

adjustment of the thermostat, and (3) the use of low temperatures programs and load optimization of washing machines and dishwashers (EDPC, not datedc).

Action (1) is a load management type of action, and the other two components are energy efficiency improvement actions. The DLV estimations considered these three components. The avoided consumption of office and audio-visual equipment is usually related to ghost consumption, either due to lack of users' care or by the nature of the equipment which is never completely switched off if the circuit is not unplugged. Action (2) was for the cooling appliances, as consumption reductions occurred due to substitution/changing the thermostat, or increased care with opening doors. Action (3) was for the washing machines and dishwashers, as the avoided consumption may result from greater care with the choice of washing programs or temperature.

According to the promoters' estimation, $22 \%$ of the annual consumption of an average residential consumer was due to office and audio-visual equipment, $28 \%$ due to refrigerators and freezers, and $16 \%$ because of dishwashers and washing machines. These estimations were considered in the estimation of the DLVs (Fig. 6). An equivalent procedure was used for the 2011-2012 PPEC edition's measures, since no other information was found.

The $\mathrm{CSkW}_{\text {peak }}$ of the information related approved measures are presented in Table 15. The $\mathrm{CSkW}_{\text {peak }}$ lasts 12 years of expected lifetime of the involved technology.

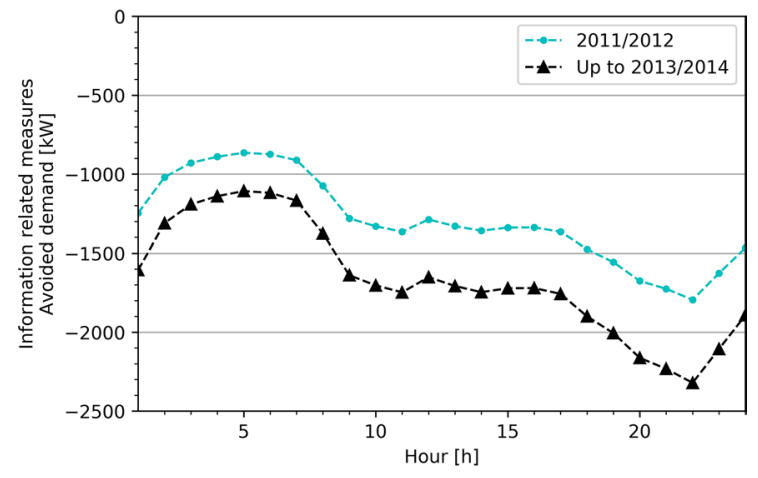

Fig. 6 Daily DLV, for working days, for each PPEC edition, regarding information measures

Table 15 The costs of each saved $\mathrm{kW}$ of peak $\left(\mathrm{CSkW}_{\text {peak }}\right)$ for the approved measures regarding information, in each PPEC edition

\begin{tabular}{lll}
\hline PPEC edition & $2011 / 2012$ & $2013 / 2014$ \\
$\mathrm{CSkW}_{\text {peak }}(€ /$ & 1135.1 & 911.2 \\
$\left.\mathrm{~kW}_{\text {peak }}\right)$ & & \\
\hline
\end{tabular}

\section{Summary: the hidden impacts revealed by the DLV}

The participation of utilities in the promotion of energy efficiency in consumption is of undeniable importance due to their proximity with the consumer. However, the full potential of those measures is currently valued by considering only avoided energy consumption, missing the power demand impact which leads to load diagram changes. As it has been 
shown in the previous section, each energy efficiency measure has more potential apart from only saving consumer's money or improving the utility image as a "green friendly" company. The consideration of the full potential of energy efficiency measures becomes even more relevant when the use of public funds is involved. Consequently, the existence of a tool to specifically assess the value of load diagram changes could be useful to both distribution system operators and regulators when designing and approving energy efficiency programs. Since load diagrams shapes and values depend on a complex set of circumstances which are not easily reproducible, which are simultaneous to the implementation of energy efficiency measures, and not solely caused by these, no load diagrams after the implementation of the measures were estimated. Instead, DLV were estimated, which resulted from the implementation of energy efficiency measures in a case study for the residential sector, approved under the Portuguese plan for the promotion of efficiency in the consumption of electricity.

In Fig. 7, the implementation of the residential measures approved under all PPEC editions are shown. It can be seen that they will contribute to a demand reduction around $37 \mathrm{MW}$ at 8 a.m. and above $77 \mathrm{MW}$,

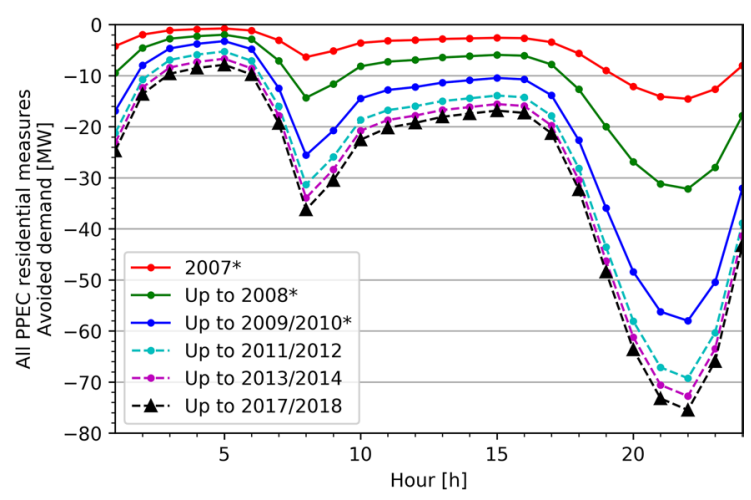

Fig. 7 Total daily diagrams of load variations for all PPEC editions

at 10 p.m. These effects are mostly due to measures addressing lighting technology change, since this was, by far, the most funded type of measure.

It is expected that the knowledge of how a measure can impact the load diagram will help utilities' decision makers to decide upon the measures to promote. For instance, it will be possible not only to know that lighting and information related energy efficiency measures are expected to have higher influence in the evening and measures addressing hot water electricity service will impact the early morning hours, but also to quantify their effects (Table 16). This quantification will be important to decide upon the expected penetration of the measures.

From the distribution systems operator perspective, and in order to more accurately estimate the changes in load diagrams due to the implementation of energy efficiency and load management measures, it is important to adopt reliable $\mathrm{M} \& \mathrm{~V}$ procedures, and to promote the realization of end uses characterization studies and monitoring campaigns. In this work, the load diagrams were estimated using results obtained from two different studies, with different populations and objectives. For illustration purposes, the data was considered suitable. Consumer behaviors change over time and from place to place. More accurate results demand more reliable data. It is in the interest of the distribution systems operator to own as reliable data as possible, in order to better decide which measures lead to the intended results. Nonetheless, it is also in the interest of the regulator to demand for $\mathrm{M} \& \mathrm{~V}$ procedures in the design of energy efficiency measures which allow a reliable assessment of load diagram changes.

\section{Conclusions and policy implications}

Diagrams of load variations (DLV) are proposed as an instrument to assess the interest of promotion of energy efficiency measures from the perspective of distribution system operators.

The multiple benefits of energy efficiency have been identified in "Energy efficiency and load management actions: drivers, impacts and assessment" as a broader view on the positive effects of energy efficiency

Table 16 Type of measures and time of day with higher contribution to demand reduction

\begin{tabular}{lllll}
\hline Time of day & 7 a.m & 9 a.m & 8 p.m & 10 p.m \\
Measure type & Load management & Water heater & Refrigerator/freezer & Lighting + information related \\
\hline
\end{tabular}


promotion. Nevertheless, two essential utilities' concerns must be considered: business sustainability and the operational constraints of the infrastructure. For decades, the electricity industry accumulated experience on influencing demand towards a better operational management of the supply side resources. In the demand-side management (DSM) portfolio of options, strategic conservation (or energy efficiency promotion) was one of the key objectives of load diagram modification.

However, the assessment of the economic or the societal interest of energy efficiency programs, dictating the prevalence of long-term energy-saving targets and the corresponding greenhouse gas emissions targets, misses the identification of indicators that are relevant for a key aspect of societal interest: the optimal planning and management of the infrastructure. In fact, the approval of such or such measures in a DSM program is (or should be) the result of an assessment, which considers several perspectives. However, the measurement and verification $(\mathrm{M} \& \mathrm{~V})$ protocols defined alongside the operative aspects of energy efficiency measures are directed at the longterm objectives of energy savings and avoided emissions, and do not benefit the acquisition of relevant information for the characterization of the effects on the load diagram to be served by the network. The proposed DLV instrument requires the existence of data which, on a perspective of targeted efficiency, should allow a high confidence level on the possible effects of an energy efficiency measure on the load diagram.

Presently, distributed generation is proliferating behind the meters, either in individual households or in energy communities. Utilities in several geographies are experiencing increasingly noticeable effects of photovoltaic production on the day-to-day management of the distribution network. The case study presented in the paper, using data which are proxy to what may be the accumulated learning experience on the effects of some energy efficiency measures, illustrates how different views can provide different decision trends regarding the implementation of certain measures. If PV was expected to have relevance on the modification of the load curve at a region served by the distribution network, two different measures would be deemed with different perspectives. In fact, the expected consequence of the introduction of heat pump-based water heating would be saving energy; however, it would also cause a simultaneous increase in the negative load gradient of the load served by the DSO in the morning, when PV starts producing. The regulator, promoting the efficiency program, would value the measure since its long-term effect would be positive, whereas the DSO could see it as an undesirable effect on the load curve. On the other hand, the two agents would converge on the benefit of the efficient lighting measure, since it would not only cause a long-term effect of energy saving, but it would also help to mitigate the possibly sharp positive gradient of load seen by the DSO when households become increasingly occupied as daylight dims and PV production ceases.

The estimated DLV can guide the assessment of the load demand effects of energy efficiency, widening the spectrum of measurable effects of energy efficiency measures, and benefiting the decision process by providing additional relevant information to decision makers.

Acknowledgements The authors would like to thank Ing. Paula Fonseca (Institute for Systems and Robotics) for sharing data from the REMODECE and EURECO projects, used in the estimation of the diagrams of load variations.

Funding This work was partially supported by the Portuguese Foundation for Science and Technology under projects UIBD/00308/2020, ESGRIDS (POCI01-0145-FEDER-016434), MAnAGER (POCI-01-0145FEDER-028040) and the Federal Institute of Santa Catarina (IFSC) international cooperation program for student exchange (N01-2018/CAMPUS FLORIANÓPOLIS).

\section{Declarations}

Conflict of interest The authors declare no competing interest.

Open Access This article is licensed under a Creative Commons Attribution 4.0 International License, which permits use, sharing, adaptation, distribution and reproduction in any medium or format, as long as you give appropriate credit to the original author(s) and the source, provide a link to the Creative Commons licence, and indicate if changes were made. The images or other third party material in this article are included in the article's Creative Commons licence, unless indicated otherwise in a credit line to the material. If material is not included in the article's Creative Commons licence and your intended use is not permitted by statutory regulation or exceeds the permitted use, you will need to obtain permission directly from the copyright holder. To view a copy of this licence, visit http://creativecommons.org/licenses/by/4.0/. 


\section{References}

Anvari, M., Lohmann, G., Wächter, M., Milan, P., Lorenz, E., Heinemann, D., \& Peinke, J. (2016). Short term fluctuations of wind and solar power systems. Journal of Physics, 18(6), 063027. https://doi.org/10.1088/1367-2630/ $18 / 6 / 063027$

California Municipal Utilities Association, 2017. Savings estimation. Technical Reference Manual. Energy Resources Solutions - Third Edition.

Biyik, E., Araz, M., Hepbasli, A., Shahrestani, M., Yao, R., Shao, L., \& Lechón, J. L. (2017). A key review of building integrated photovoltaic (BIPV) systems. Engineering Science and Technology, an International Journal, 20(3), 833-858. https://doi.org/10.1016/j.jestch.2017. 01.009

Borland, J.; Singh, A., 2018. Reducing Morning \& late afternoon grid-buy demand by engineering box-like rooftop solar-PV generation profiles without the high cost of trackers or bifacial panels. IEEE $7^{\text {th }}$ World Conference on Photovoltaic Energy Conversion (WCPEC), pp. 1169-1172.

CAISO, 2016. What the duck curve tells us about managing a green grid - Fast facts, California Independent System Operator. California ISO Fast Facts. https://www.large. stanford.edu/courses/2015/ph240/burnett2/docs/flexible. pdf (accessed 08 october 2021).

CEC, 2002. Demand-side management - End-use metering campaign in 400 households of the European Community - Assessment of the Potential Electricity Savings, Project EURECO. Commission of European Communities. http:// www.eerg.it/resource/pages/it/Progetti_-_MICENE/final reporteureco2002.pdf (accessed 18 July 2020).

CPUC, 2001. California Standard Practice Manual Economic Analysis of Demand-Side Programs and Projects. Edison Electric Institute: Washington, DC, USA. https://www. raponline.org/wp-content/uploads/2016/05/cpuc-standardpr actice-manual-2001-10.pdf (accessed 08 october 2021).

Crossley, D., 2010. International best practice in using energy efficiency and demand management to support electricity networks. Australian Alliance to Save Energy by Energy Futures Australia.

Deason, W. (2018). Comparison of $100 \%$ renewable energy system scenarios with a focus on flexibility and cost. Renewable and Sustainable Energy Reviews, 82, 31683178. https://doi.org/10.1016/j.rser.2017.10.026

Denholm, P.; O'Connell, M.; Brinkman, G.; Jorgenson, J., 2015. Overgeneration from solar energy in California. A field guide to the duck chart. National Renewable Energy Lab. - No. NREL/TP-6A20-65023, Golden, CO (EUA).

Doroshenko, M.; Keshav, S.; Rosenberg, C., 2018. Flattening the duck curve using grid-friendly solar panel orientation. Proceedings of the Ninth International Conference on Future Energy Systems, pp. 375-377.

EDPC, not dateda. Standby killer - Telecomando, Medidas Tangíveis PPEC 11/12. EDP Comercial.

EDPC, not datedb. Kit casa eficiente (LED + Standby killer), MedidasTangíveis PPEC 11/12. EDP Comercial.

EDPC, not datedc. Measure Me - Residencial, Medidas Tangíveis PPEC 13/14. EDP Comercial.
EDPSU, not dated. Multitomada inteligente - Residencial, Medidas Tangíveis PPEC 13/14. EDP Serviço Universal.

Efficiency Vermont, 2018. Technical Reference User Manual (TRM) - Measure savings algorithms and cost assumptions. Efficiency Vermont.

ERSE, 2007a. Plano de Promoção da Eficiência no Consumo de Energia Elétrica para 2007. Entidade Reguladora dos Serviços Energéticos, Lisboa. https://www.erse.pt/media/ tznlauor/ppec2007_final_jan07-1.pdf (accessed 18 July 2020).

ERSE, 2007b. Plano de Promoção da Eficiência no Consumo de Energia Elétrica para 2008. Entidade Reguladora dos Serviços Energéticos, Lisboa. https://www.erse.pt/media/ xtznbsjc/ppec2008final.pdf (accessed 18 July 2020).

ERSE, 2009. Plano de Promoção da Eficiência no Consumo de Energia Elétrica para 2009-2010. Entidade Reguladora dos Serviços Energéticos, Lisboa. https://www.erse.pt/ media/r44lehli/documentoppec20092010.pdf (accessed 18 July 2020).

ERSE, 2010. Plano de Promoção da Eficiência no Consumo de Energia Elétrica para 2011-2012. Entidade Reguladora dos Serviços Energéticos, Lisboa. https://www.erse.pt/ media/yasjf5lc/ppec2011-2012.pdf (accessed 18 July 2020).

ERSE, 2011. PPEC 2007 - Balanços e Resultados. Entidade Reguladora dos Serviços Energéticos, Lisboa. https:// www.erse.pt/media/youhvmrz/relat\% C3\%B3rio-anualppec2007-final.pdf (accessed 18 July 2020).

ERSE, 2013. Plano de Promoção da Eficiência no Consumo de Energia Elétrica para 2013-2014. Entidade Reguladora dos Serviços Energéticos, Lisboa. https://www.erse.pt/ media/ipyixdzu/relat\%C3\%B3rio-final-ppec_dez2013.pdf (accessed 18 July 2020).

ERSE, 2014a. Plano de Promoção da Eficiência no Consumo de Energia Elétrica (PPEC 2008) - Período de implementação 2008-2011 - Balanços e Resultados. Entidade Reguladora dos Serviços Energéticos, Lisboa. https:// www.erse.pt/media/1dahspyr/relat\%C3\%B3rio-execu\% C3\%A7\%C3\%A3o-ppec2008-final.pdf (accessed 18 July 2020).

ERSE, 2014b. Plano para a Promoção da Eficiência no Consumo de Energia Elétrica para 2013-2014 - Impactes e benefícios das medidas aprovadas. Entidade Reguladora dos Serviços Energéticos, Lisboa. https://www.erse.pt/ media/vlnp4wez/doc-medidasaprovadasppec2013-2014final.pdf (accessed 18 July 2020).

ERSE, 2016a. Plano para a Promoção da Eficiência no Consumo de Energia Elétrica para 2017-2018. Entidade Reguladora dos Serviços Energéticos, Lisboa. https:// www.erse.pt/media/r2bbevgl/relat\%C3\%B3rio-erse-dgegde-avalia\% C3\% A7\% C3\% A3o-do-ppec-2017-2018.pdf (accessed 18 July 2020).

ERSE, 2016b. Plano para a Promoção da Eficiência no Consumo de Energia Elétrica para 2013-2014 - Impactes e benefícios das medidas aprovadas. Entidade Reguladora dos Serviços Energéticos, Lisboa. https://www.erse.pt/ media/gdadqt0j/ppec2017-2018-doc-medidas-aprovadasfinal.pdf (accessed 18 July 2020).

ERSE, 2017a. Plano de Promoção da Eficiência no Consumo de Energia Elétrica para 2017-2018 - Impactes e benefícios das medidas aprovadas. Entidade Reguladora dos 
Serviços Energéticos, Lisboa. https://www.erse.pt/media/ gdadqt0j/ppec2017-2018-doc-medidas-aprovadas-final. pdf (accessed 18 July 2020).

ERSE, 2017b. Plano de promoção da eficiência no consumo de energia elétrica (PPEC 2009-2010) - Período de implementação 2009 - 2012 - Balanço e resultados. Entidade Reguladora dos Serviços Energéticos, Lisboa. https:// www.erse.pt/media/qbzjguys/relat\%C3\%B3rio-execu\% C3\%A7\%C3\%A3o-ppec2009-10-final.pdf (accessed 18 July 2020).

Freitas, S., \& Brito, M. (2019). Non-cumulative only solar photovoltaics for electricity load-matching. Renewable and Sustainable Energy Reviews, 109, 271-283. https://doi. org/10.1016/j.rser.2019.04.038

Gellings, C. (2017). Evolving practice of demand-side management. Journal of Modern Power Systems and Clean Energy, 5(1), 1-9. https://doi.org/10.1007/ s40565-016-0252-1

Hou, Q., Zhang, N., Du, E., Miao, M., Peng, F., \& Kang, C. (2019). Probabilistic duck curve in high PV penetration power system: Concept, modelling, and empirical analysis in China. Applied Energy, 242, 205-215. https://doi.org/ 10.1016/j.apenergy.2019.03.067

ICER, 2010. A description of current regulatory practices for the promotion of energy efficiency - A presentation of information gathered from the world's energy markets on regulatory practices aimed at fostering energy efficiency. International Confederation of Energy Regulators - Ref. I10-CC-02-04, 2010.

IEA, 2014. Capturing the multiple benefits of energy efficiency. International Energy Agency.

ISR-UC, 2008. Residential monitoring to decrease energy use and carbon emissions in Europe, lessons learned and next steps. Institute of Systems and Robotics, University of Coimbra. https://www.remodece.isr.uc.pt/downloads/ REMODECE_PublishableReport_Nov2008_FINAL. pdf (accessed 08 October 2021).

Johnson, E., Beppler, R., Blackburn, C., Staver, B., Brown, M., \& Matisoff, D. (2017). Peak shifting and cross-class subsidization: The impacts of solar PV on changes in electricity costs. Energy Policy, 106, 436-444. https://doi.org/10. 1016/j.enpol.2017.03.034

Kind, P., 2013. Disruptive challenges: Financial implications and strategic responses to a changing retail electric business. Edison Electr. Inst. 26. https://www.ourenergyp olicy.org/wp-content/uploads/2013/09/disruptivechall enges-1.pdf (accessed 29 September 2018).

Lazar, J., 2016. Teaching the "duck" to fly. Second Edition. Montpelier, VT: The Regulatory Assistance Project. Available online: https://www.raponline.org/wp-content/ uploads/2016/05/rap-lazar-teachingtheduck2-2016-feb-2. pdf. Accessed 8 Oct 2021

Majzoobi, A.; Khodaei, A., 2016. Application of microgrids in addressing distribution network net-load ramping. IEEE Power \& Energy Society Innovative Smart Grid Technologies Conference (ISGT), pp. 1-5.

Moura, P. S., \& de Almeida, A. T. (2010). The role of demandside management in the grid integration of wind power. Applied Energy, 87, 2581-2588. https://doi.org/10.1016/j. apenergy.2010.03.019

Nadel, S.; Herndon, G., 2014. The future of the utility industry and the role of energy efficiency. American Council for an Energy-Efficient Economy, Report Number U1404. https://www.aceee.org/sites/default/files/publications/ researchreports/u1404.pdf (accessed 31 October 2018).

National Plan for Energy Efficiency, 2008. Understanding costeffectiveness of energy efficiency programs: Best practices, technical methods, and emerging issues for policymakers. Energy and Environmental Economics, Inc. and Regulatory Assistance Project. https://www.epa.gov/sites/ production/files/2015-08/documents/cost-effectiveness. pdf (accessed 22 July 2020).

Neme, C.; Grevatt, J., 2015. Energy efficiency as a T\&D resource: Lessons from recent U.S. efforts to use geographically targeted efficiency programs to defer T\&D investments. Northeast Energy Efficiency Partnerships.

Rai, A., Esplin, R., Nunn, O., \& Nelson, T. (2019). The times they are a changin': Current and future trends in electricity demand and supply. The Electricity Journal, 32, 24-32. https://doi.org/10.1016/j.tej.2019.05.017

RAP, 2012. Best practices in designing and implementing energy efficiency obligation schemes. Task XXII of the International Energy Agency - Demand Side Management Programme, The Regulatory Assistance Project.

Sousa, J., Martins, A., \& Jorge, H. (2013). World-wide nonmandatory involvement of electricity utilities in the promotion of energy efficiency and the Portuguese experience. Renewable and Sustainable Energy Reviews, 22, 319-331. https://doi.org/10.1016/j.rser.2013.02.006

Sousa, J., Martins, A., \& Jorge, H. (2013). Dealing with the paradox of energy efficiency promotion by electric utilities. Energy, 57, 251-258. https://doi.org/10.1016/j. energy.2013.02.040

Sousa, J.; Soldi, R.; Martins, A.; Pont, I.; Friedrich, A., 2019. Can west-facing PV panels help the grid during the sunset? A study with Portuguese consumers. Proceedings of the 18th International Conference on Sustainable Energy Technologies, Energy \& Environment Research, 223-230, Kuala Lumpur, Malaysia.

Tarr, K.E., 2018. The energy imbalance market: Environmental benefits of regional market integration in the West. Integration in the West. WWU Honors Program Senior Projects - 74.

Torabi, R., Gomes, A., Morgado-Dias, F., 2018. The duck curve characteristic and storage requirements for greening the Island of Porto Santo. Energy and Sustainability for Small Developing Economies (ES2DE), pp. 1-7. https:// doi.org/10.1109/ES2DE.2018.8494235.

Trust, E. M. (2020). Retail/residential technical reference manual. Efficiency Main Trust - Version, 2020, 5.

York, D.; Bastian, H.; Relf, G.; Amann, J., 2017. Transforming energy efficiency markets, lessons learned and next steps. American Council for an Energy-Efficient Economy, Report Number U1715. https://www.aceee.org/sites/defau 1t/files/publications/researchreports/u1715.pdf (accessed 18 June 2020).

Publisher's note Springer Nature remains neutral with regard to jurisdictional claims in published maps and institutional affiliations. 